Revista Tecnologia e Ambiente, v. 21, 2014, Criciúma, Santa Catarina. ISSN: 1413-8131 (versão

impressa) ISSN: 2358-9426 (versão eletrônica)

\title{
PATRIMÔNIO MATERIAL EDIFICADO DE SOMBRIO (SANTA CATARINA, BRASIL): MEMÓRIA E IDENTIDADE ${ }^{1}$
}

\section{BUILT HERITAGE OF SOMBRIO (SANTA CATARINA, BRAZIL): MEMORY AND IDENTITY}

\section{RESUMO}

\author{
Taise Correia dos Santos $^{2}$ \\ Carlos Passos Paulo Matias ${ }^{3}$ \\ Marcos Cesar Pereira Santos ${ }^{4}$ \\ Juliano Bitencourt Campos 5
}

\begin{abstract}
A preservação dos bens culturais de uma comunidade é um compromisso social que está diretamente ligado ao exercício da cidadania. Compromisso este que extrapola questões políticas/legislativa e/ou econômicas e avança por questões sociais, de identidade, de pertencimento. Questões que forçosamente fazem um apelo ao debate, às discussões com a população e com organizações sociais. Nesta perspectiva é que se iniciou esta pesquisa. Buscamos fazer um (re)visitação ao Patrimônio Histórico Edificado do Município de Sombrio. Buscou-se também registrar potenciais edificações históricas que a nosso entender fazem parte da história de Sombrio, logo fazem parte do Patrimônio Edificado. Acreditamos que assim, a história, o historiador e as pesquisas interdisciplinares podem contribuir com a sociedade nas discussões/conhecimento daquilo que nos torna sociais e pertencentes de uma identidade cultural.
\end{abstract}

Palavras-chave: Patrimônio. Memória. Identidade. Sombrio.

\begin{abstract}
The conservation of cultural assets of a community is a social commitment directly related to citizenship. This commitment goes beyond political/legislative and/or economic issues and proceeds in social issues and matters of identity and ownership. Those issues strongly require debate and discussions with the community and the social organizations. This research began in this perspective. We sought to (re)visit the Historic Built Heritage of the Municipality of Sombrio. We attempted also to register potential historic buildings that we believe are part of Sombrio`s history, therefore part of its Built Heritage. We believe that in this way history, historian and interdisciplinary researches can contribute with the society to the debate/knowledge of what make us social and owners of a cultural identity.
\end{abstract}

Keywords: Heritage. Memory. Identity. Sombrio.

\section{INTRODUÇÃO}

\footnotetext{
${ }^{1}$ Parte do Trabalho de Conclusão de Curso (TCC), Bacharelado em História, do primeiro autor.

${ }^{2}$ Graduada em História pela Universidade do Extremo Sul Catarinense - UNESC.

${ }^{3}$ Setor de Arqueologia. Pesquisador do Grupo de Pesquisa Arqueologia e Gestão Integrada do Território da Universidade do Extremo Sul Catarinense - UNESC, Criciúma, SC. E-mail: cpp@ unesc.net

${ }^{4}$ Setor de Arqueologia. Pesquisador do Grupo de Pesquisa Arqueologia e Gestão Integrada do Território da Universidade do Extremo Sul Catarinense - UNESC, Criciúma, SC.

${ }^{5}$ Setor de Arqueologia. Pesquisador do Grupo de Pesquisa Arqueologia e Gestão Integrada do Território da Universidade do Extremo Sul Catarinense - UNESC, Criciúma, SC.
} 

impressa) ISSN: 2358-9426 (versão eletrônica)

As discussões referentes aos patrimônios são frequentes na academia e fora dela. A preservação dos bens culturais de uma comunidade é um compromisso social que está diretamente ligado ao exercício da cidadania. Compromisso este que extrapola questões políticas/legislativas e/ou econômicas e avança por questões sociais, de identidade, de pertencimento, enfim, questões que forçosamente fazem um apelo ao debate, às discussões com a população e com organizações sociais.

Inicialmente houve a preocupação em contextualizar o objeto de pesquisa, buscando na legislação informações que legitimassem a importância do patrimônio histórico para a comunidade e ressaltando o compromisso social da população.

Toda e qualquer proposta de estudo da questão do patrimônio históricocultural que pretenda mais que o simples conhecimento dos bens oficialmente existentes, deve buscar estabelecer relações entre este e os conceitos de memória, identidade e cidadania, sem os quais se corre o risco de simplesmente reforçar determinadas lembranças que, consagradas pelo uso e pelo tempo, acabam sendo transformadas em sinônimo da verdade sobre o passado, construído de forma unilateral (SALVADORI, 2008. p. 26).

Na perspectiva dos novos campos de investigação, trazidos pela Nova História (BURKER, 1997), onde se problematiza partindo dos conceitos de cultura, memória e identidade, a fim da melhor compreensão sobre a noção de Patrimônio Material Edificado, sabe-se que a preservação desses, mantem vivas relações sociais, significados e valores, atribuídos a uma determinada cultura. "Em outras palavras, o patrimônio não é apenas o objeto - material ou imaterial - preservado, mas as práticas, atitudes, significados e valores dos quais o objeto é um suporte de informação; é um processo humano que lhe confere valor" (SALVADORI, 2008, p. 26).

Iniciaremos nossa discussão refletindo sobre a questão que nos coloca uma realidade visível sobre o Patrimônio Histórico Edificado de Sombrio. Atualmente notase pouca preocupação dos moradores da cidade de Sombrio em preservar os bens culturais que fazem parte da memória e identidade da região, bem como ações que podemos chamar de paliativas em relação ao patrimônio desta cidade. Assim, na condição de exercício de cidadania, este trabalho coloca-se como um instrumento de diálogo na elaboração e melhoramento de politicas públicas de preservação e socialização do Patrimônio Histórico Edificado de Sombrio.

De acordo com o artigo 216 da Constituição Federal de 1988: 
Revista Tecnologia e Ambiente, v. 21, 2014, Criciúma, Santa Catarina. ISSN: 1413-8131 (versão impressa) ISSN: 2358-9426 (versão eletrônica)

imaterial, tomados individualmente ou em conjunto, portadores de referência à identidade, à ação, à memória dos diferentes grupos formadores da sociedade brasileira, nos quais se incluem:

I - as formas de expressão;

II - os modos de criar, fazer e viver;

III - as criações científicas, artísticas e tecnológicas;

IV - as obras, objetos, documentos, edificações e demais espaços destinados às manifestações artístico-culturais;

$\mathrm{V}$ - os conjuntos urbanos e sítios de valor histórico, paisagístico, artístico, arqueológico, paleontológico, ecológico e científico (C.F., 1988, Art. 216).

Seguindo a perspectiva da Constituição Federal quanto à proteção e identificação daquilo que constitui nosso Patrimônio, trazemos o que temos de concreto no município de Sombrio referente à Lei. Na legislação de Sombrio encontra-se o COMPAC, Conselho Municipal do Patrimônio Cultural de Sombrio, Lei n ${ }^{\circ} 1402$ de 20 de março de 2003:

Art. $5^{\circ}$ - Fica criado o Conselho Municipal do Patrimônio Cultural COMPAC, órgão de caráter deliberativo e consultivo, integrante da Secretaria Municipal de Educação, Cultura e Esportes.

$\S 1$ - O conselho será composto pelo Prefeito Municipal de Sombrio, na condição de Presidente, pelo Secretário Municipal de Educação, Cultura e Esportes, na condição de secretário, pelo Secretário Municipal de Turismo, pelo Diretor Municipal do Meio Ambiente, por um representante da Biblioteca Pública Municipal, por representantes do Patrimônio Histórico da Fundação Catarinense de Cultura - FCC e por mais cinco membros nomeados pelo Prefeito Municipal por indicação do Secretário Municipal de Educação, Cultura e Esportes.

$\S 2$ - Entre os cinco membros nomeados pelo Prefeito deverá haver um historiador ou um professor de história e um arquiteto ou um engenheiro civil, devidamente inscritos em suas entidades representativas e os demais serão escolhidos nas diversas profissões ligadas às áreas cultural e de meio ambiente (Prefeitura Municipal de Sombrio, 2003, Lei 1402).

Quanto aos bens protegidos por lei, chamou-nos a atenção o fato de que a única Lei que declara um patrimônio público refere-se às figueiras, como segue:

LEI N ${ }^{\circ}$ 1080, DE 14 DE JUNHO DE 1996

"DECLARA PATRIMÔNIO PÚBLICO TODAS AS FIGUEIRAS EXISTENTES NO MUNICÍPIO"

O Prefeito Municipal de Sombrio-SC. Faço saber a todos os habitantes do Município que a Câmara Municipal aprovou e eu sanciono a seguinte Lei:

Art. $1^{\circ}$ - Todas as Figueiras existentes do Município de Sombrio passam a integrar o patrimônio público, ficando proibida sua derrubada, sob qualquer hipótese (Prefeitura Municipal de Sombrio, 1996, Lei 1080).

\section{PATRIMÔNIO MATERIAL EDIFICADO}

A identidade cultural de um povo pode ser expressa de várias maneiras, através 

impressa) ISSN: 2358-9426 (versão eletrônica)

da arte, da religiosidade, das danças, das vestes e também através de suas edificações. As edificações sempre carregam consigo aspectos culturais e sociais da sociedade e do meio daqueles que construíram, quando estas construções passam a ter um valor simbólico e/ou histórico tornam-se os chamados lugares de memória.

Mas as edificações não são apenas locais de abrigo, tão importantes para o surgimento e desenvolvimento das civilizações. Poderíamos dizer que as edificações são como livros que contam histórias, porém, enquanto nos livros são as palavras que nos trazem significados, nos edifícios são as formas, os materiais, os contextos espaciais que podem nos dizer muitas coisas acerca de um determinado povo e de um determinado lugar (ARGAN, 2003).

Sabendo que essas construções, ou melhor, patrimônios materiais edificados, sofrem impactos e desgaste recorrente dos efeitos do tempo e do crescimento urbano surge à preocupação com sua preservação. A preservação dos patrimônios materiais edificados (prédios, casas, lugares sagrados, escolas...) não se remete apenas a manter de pé antigas construções, vai além, mantem viva as relações sociais, significados e valores atribuídos a uma determinada cultura. "Quando se luta pela permanência de um bem são as relações humanas que lá se estabeleceram que deve vir a tona e nossa compreensão sobre ela. O que se preserva não é uma 'coisa', mas um dado da cultura" (SALVADORI, 2008, p. 26).

Entre os patrimônios materiais edificados destacam-se na região de sombrio:

- Lugares sagrados: são os lugares que evocam uma memória religiosa, de acordo com Ostetto et al. (2001, p. 9): “A visibilidade imediata de sua existência nas cidades se materializa na arquitetura dos templos religiosos, nos cemitérios, monumentos referentes a santos, pinturas sacras que se transformam em indícios de uma memória religiosa".

- Casas e prédios: são as construções arquitetônicas, comércio, indústrias, escolas, prédios ou simplesmente casas que carregam em sua edificação aspectos culturais e sociais da região. "A casa, moradia, a indústria, as ruas e as cidades constituem um parâmetro básico não apenas de orientação geográfica mas, principalmente, de localização social” (SALVADORI, 2008, p. 49).

- Museus: são espaços onde se busca a preservação da memória a partir de materiais pertencentes a uma sociedade, segundo o Diagnóstico produzido pelo setor de Arqueologia da UNESC: "Os museus também se destacam como espaços privilegiados 
Revista Tecnologia e Ambiente, v. 21, 2014, Criciúma, Santa Catarina. ISSN: 1413-8131 (versão impressa) ISSN: 2358-9426 (versão eletrônica)

da memória de uma cidade, exibindo em seus expositores exemplos da cultura material dos diferentes grupos humanos" (IPAT/UNESC, 2006, p. 14).

- Monumentos: de acordo com a Convenção Relativa ao Patrimônio Mundial, Cultural e Natural de 1972, Art. $1^{\circ}$ os monumentos são concebidos como:

...obras arquitetônicas, de escultura ou de pintura monumentais, elementos ou
estruturas de natureza arqueológica, inscrições, cavernas e grupos de
elementos que tenham um valor universal e excepcional do ponto de vista da
história, da arte ou da ciência (SILVA, 2012. p. 89).

- Engenhos: era nos engenhos que a matéria-prima, através das atividades artesanais, se transformava em produtos para o consumo.

Os engenho de farinha começaram a aparecer com a colonização açoriana entre 1748 a 1756. Estatísticas indicam que em 1794 existiam cerca de 382 deles em Santa Catarina. O Engenho é, assim, um "equipamento industrial", numa combinação de engrenagens, confeccionadas de maneira que operam com eixos de 90 graus entre eles, articulando a roda "sevadeira" com a "entrosga ou bolandeira ou roda grande", que movimenta a "hélice de abanar" o forno (ARAÚJO, s/d).

\section{METODOLOGIA}

A metodologia empregada no desenvolvimento do trabalho foi dividida nas seguintes etapas: Revisão bibliográfica. Investigação junto aos órgãos públicos sobre possíveis patrimônios tombados. Visitação aos Patrimônios Edificados do Município de Sombrio que aparecem na literatura do município, buscando informações sobre o mesmo. Registro e visitação a potenciais patrimônios que aparecem ou não na literatura do município que trata do assunto, como: Engenhos de Farinha e construções históricas.

\section{SOMBRIO: BREVE HISTÓRICO E LOCALIZAÇÃO}

Dentre tantas histórias, conta-se que a cidade de Sombrio foi nomeada não por ser um lugar sombrio do termo assustador, mas sim por possuir enormes figueiras que propiciavam sombra para os que ali passavam. No livro "Sombrio 85 anos", o autor confirma esta afirmação: “Outra hipótese levantada, a aceita pelo autor, é de que os tropeiros, ao tangerem o gado pela região, alimentavam suas boiadas junto à lagoa, antes de se aventurarem na subida da serra, utilizando a sombra das figueiras para repousarem" (FARIAS, 2000). 

impressa) ISSN: 2358-9426 (versão eletrônica)

O município se limita ao norte com Araranguá e Ermo, ao sul com Santa Rosa do Sul, a oeste com Jacinto Machado e a leste com Balneário Gaivota (Figura 1). Possui em torno de 25.000 habitantes, segundo o Censo Demográfico 2010 (IBGE, 2014).

Figura 1 - Localização Geográfica do município de Sombrio.

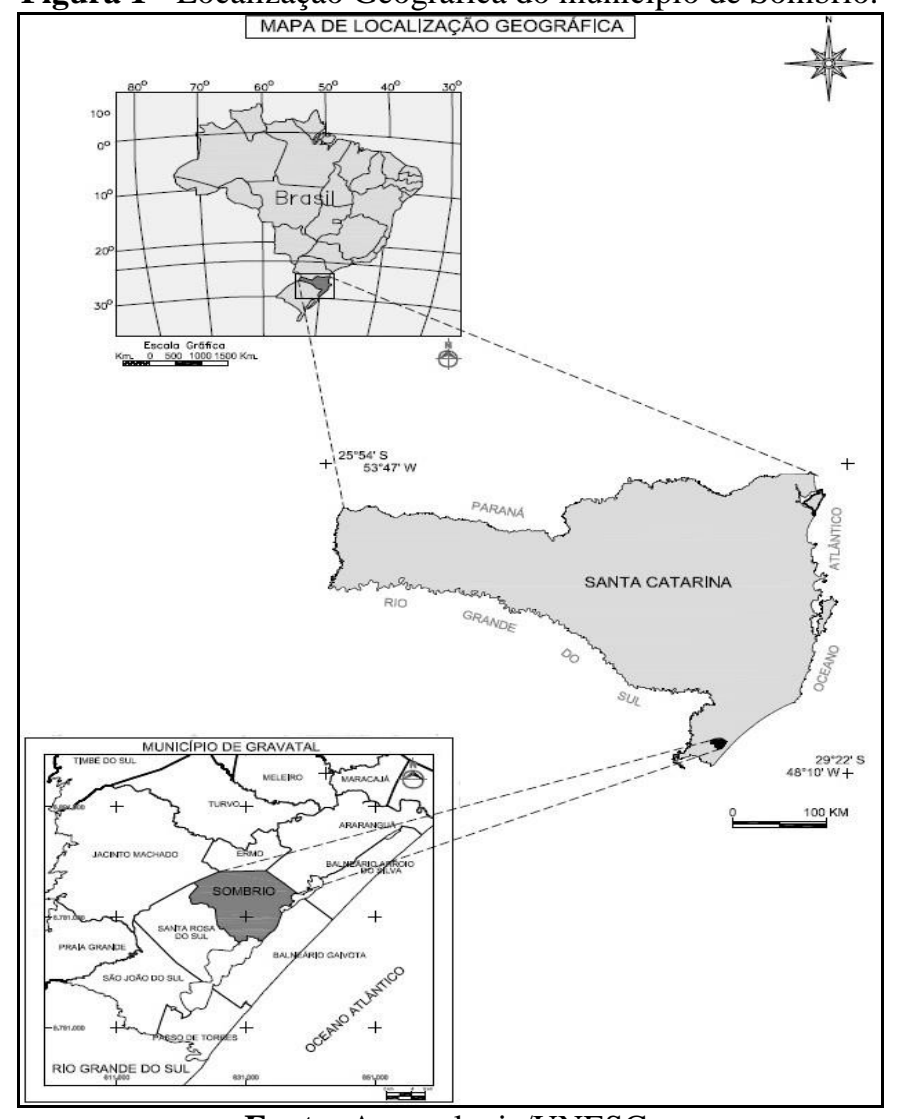

Fonte: Arqueologia/UNESC.

A cidade fica localizada no extremo Sul de Santa Catarina, possui uma das maiores lagoas do estado e no plantio destacam-se o fumo, o arroz, a mandioca, a banana, o feijão e o milho, no comércio destacam-se a produção têxtil e cerâmica. Sendo a produção de polvilho uma das atividades econômicas presente na região, a rosca de polvilho assada e a rosca de polvilho frita são consideradas comidas tradicionais na cidade. Os teares de confeccionar tapetes antes tão comuns na região agora são poucos, além dos trabalhos artesanais que também segue um processo de diminuição com o crescimento do comércio e da indústria.

Os primeiro habitantes, os grupos indígenas, "foram aos poucos sendo eliminados ou afastados das terras sombrienses a partir do momento em que os 
Revista Tecnologia e Ambiente, v. 21, 2014, Criciúma, Santa Catarina. ISSN: 1413-8131 (versão impressa) ISSN: 2358-9426 (versão eletrônica)

primeiros brancos de origem europeia chegaram à região no século XVII" (FARIAS, 2000).

Tem-se o nome de João José Guimarães como um dos primeiros europeus a fixar residência em Sombrio. Conta-se que após um ataque dos índios à sua fazenda, em Chimarrão, tendo eles matado sua esposa, João José foge para Sombrio com alguns dos seus filhos e com escravos. As Furnas serviram de abrigo à família por muito tempo. "João José foi, pois o primeiro proprietário de terras sombrienses, adquirindo do Estado, em 1833, vasta extensão de terras com 1130 braças de frente por 3000 de fundos, indo do litoral até o travessão geral" (FARIAS, 2000).

Uma manifestação cultural que se evidencia na região de Sombrio tem origem açoriana, trazidas por famílias que migraram por todo litoral de Santa Catarina até Rio Grande do Sul. "A comunidade de Sombrio resultou do povoamento luso-açoriano iniciado na primeira metade do século XX, e manteve um fluxo constante de novos povoadores ao longo do século XX" (FARIAS, 2000).

Como em todas as cidades, Sombrio tem seus pontos turísticos, como o Calçadão Cultural, o Museu ao ar livre, a tradicional festa do padroeiro Santo Antônio, o Arraial Fest, o Morro da Moça, as Furnas, entre outros.

Arraial Fest é o principal evento que ocorre na cidade, festa típica açoriana que acontece a cada dois anos com shows, eventos e apresentações, onde se reúnem não só a população local, mas também muitos turistas. Oficinas de dança típica açoriana são realizadas e apresentadas nos eventos da cidade e nas historiografias mais antigas a "cultura açor" é exaltada. Certamente que Sombrio apesar de ser uma cidade pequena é repleta de histórias, de objetos e lugares que para os moradores tem valor inestimável.

\section{REVISITANTO E AMPLIANDO O PATRIMÔNIO HISTÓRICO}

Desde 1938 buscava-se recursos para a construção da Igreja Matriz, em janeiro de 1940 o projeto da Igreja Santo Antônio de Pádua foi produzido pelo engenheiro civil Felippe Bündgens, de Florianópolis. Foi o Padre João Adão Reitz (Sacerdote Diocesano, $1^{\circ}$ Pároco de Sombrio) quem iniciou a obra. Nascido no município de Antônio Carlos, SC, este padre veio para Sombrio em 06-12-1937, e morreu aos 80 anos na cidade. João Reitz aparece nos registros escritos da cidade e muitas vezes é enaltecido, como a seguir: 

impressa) ISSN: 2358-9426 (versão eletrônica)

Este sentimento e desejo de melhoramento, de ter uma igreja grande, bonita, era expresso através de atas e campanhas que o povo por sua própria conta fazia. Mas, ninguém dentre os leigos e nem os padres que antecederam ao $1^{\circ}$ vigário tiveram a coragem de iniciar uma obra nessas proporções. Foi necessária e providencial a vinda e a garra do Padre João Adão Reitz para que Sombrio começasse a crescer (ROSA, 2012, p. 20).

A Igreja Matriz foi construída de frente para a avenida principal, estratégia para que todos que entrassem na cidade se deparassem com a enorme construção. Isso tornou-se possível na medida em que foi o próprio Padre João Reitz quem traçou as ruas e avenidas da sede de Sombrio.

Em 1940, após um mutirão de limpeza do terreno onde seria construída a igreja, foi realizado o Lançamento da Pedra Fundamental da Matriz, iniciando-se a obra. Em maio de 1963 foi realizada a inauguração e bênção da Igreja Matriz (figura 2). As pinturas e relevos feitos no interior da igreja pelo artista Zé Diabo iniciaram-se em julho de 1991 e finalizaram-se em fevereiro de 1994.

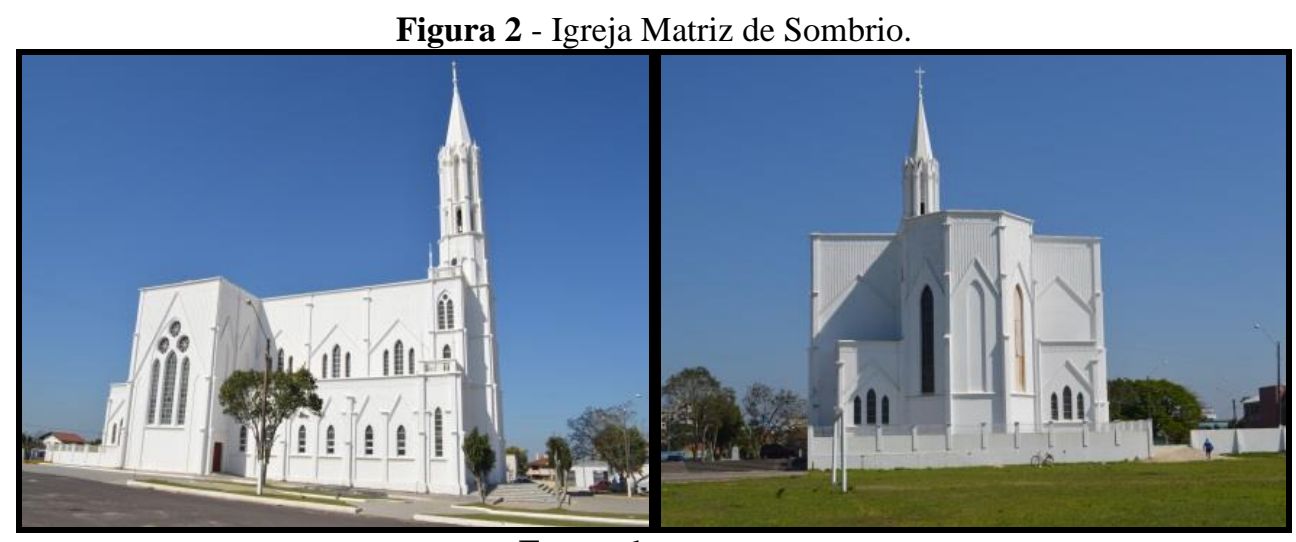

Fonte: dos autores.

Construída no ano de 1929 a casa onde residia D. Jovi (figura 3) fica localizada no centro da cidade, próximo à prefeitura. Fala-se que é o único bem material edificado tombado em Sombrio, porém nenhuma lei foi encontrada no processo de pesquisa, sendo que seu interior foi modificado, conservando-se apenas a fachada, que atualmente apresenta maus cuidados. Os materiais utilizados para a construção das casas da época eram o barro, tijolos e a pedra de cal. Apesar da arquitetura chamar atenção de quem passa, as características não lembra a cultura açoriana, pouco se sabe e se conhece sobre a história desta que é uma das construções mais antigas que sobrevive no centro da cidade. 
Revista Tecnologia e Ambiente, v. 21, 2014, Criciúma, Santa Catarina. ISSN: 1413-8131 (versão impressa) ISSN: 2358-9426 (versão eletrônica)

Figura 3 - Casa Onde Residia D. Jovi.

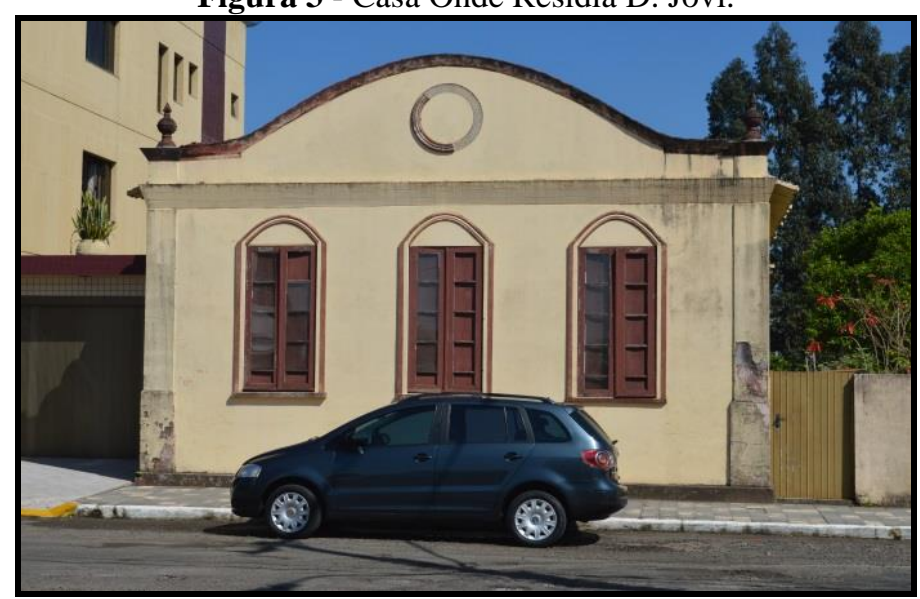

Fonte: dos autores.

A antiga Sapataria (figura 4) pertencia ao Sr. Delfino Sant'Helena e atualmente pertence ao seu filho Sr. Hélio de Quadros Sant'Helena. A construção possui a aproximadamente uns 60 anos. As intervenções feitas foram apenas para garantir o uso. Esta que representa a importância da indústria do sapato para a economia do município hoje serve de escritório de contabilidade da família.

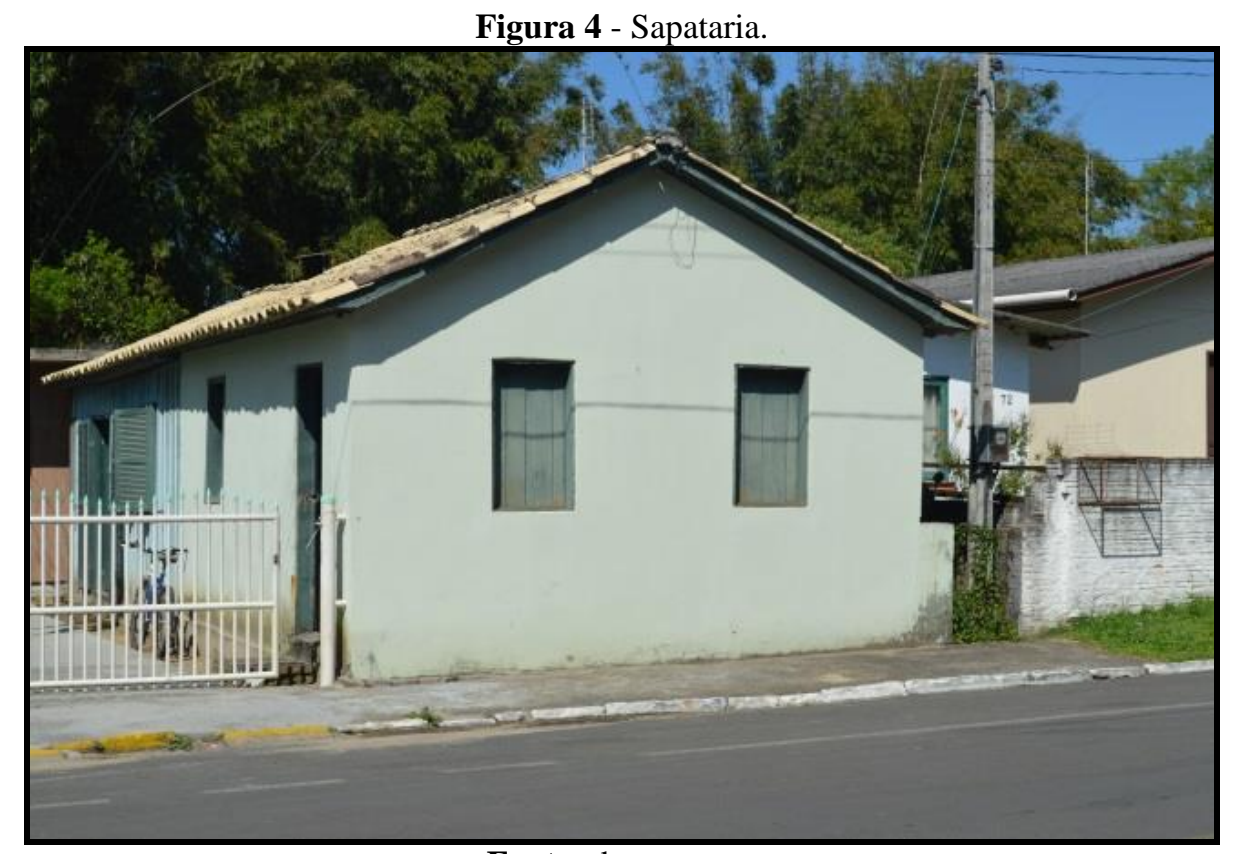

Fonte: dos autores.

Esta edificação era a entrada para o estádio Cairú, que pertencia ao Ipiranga Futebol Clube Sociedade Esportiva, fundado em 1933.

Em 20 de março de 1933 fazia-se uma reunião a fim de organizar uma sociedade esportiva e recreativa, reunindo diversas pessoas na residência do 
Revista Tecnologia e Ambiente, v. 21, 2014, Criciúma, Santa Catarina. ISSN: 1413-8131 (versão impressa) ISSN: 2358-9426 (versão eletrônica)

senhor Domício Pereira, onde todos aprovaram a ideia, tendo sido sugerido que esta sociedade tomaria o nome de Ipiranga Futebol Clube, servindo-se das cores azul e branco (PEREIRA, 1972, p. 80).

O estádio não era coberto, Sr. Hélio de Quadros Sant'Helena, morador de Sombrio, dono da antiga sapataria, diz que no estádio havia uma cerca de madeira envolta e que a grama teria sido colocada a mão. A entrada do estádio (figura 5) foi pintada e reformada para ali funcionar uma feira, não há nenhuma placa informativa ou nenhum vestígio que lembre o Ipiranga Futebol Clube.

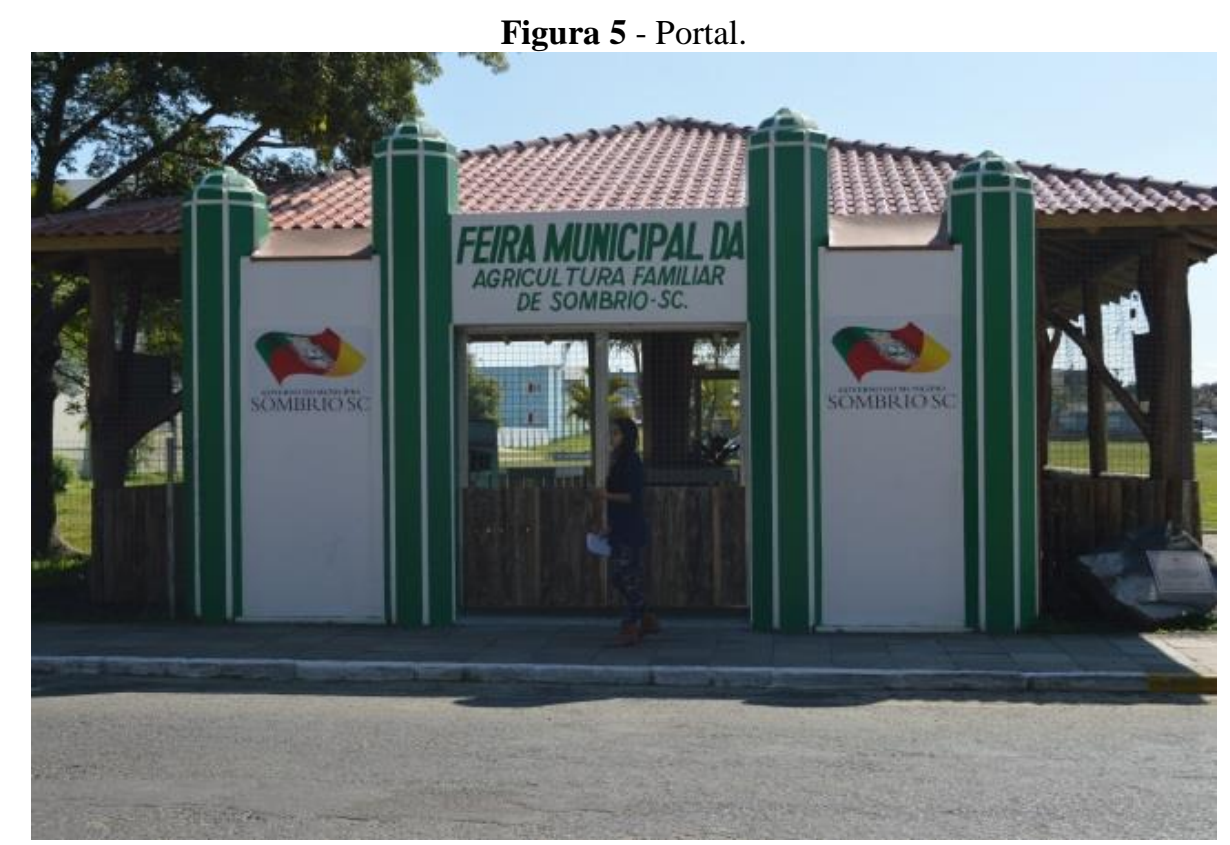

Fonte: dos autores.

O prédio onde hoje se encontra a Biblioteca Pública Municipal Cônego João Reitz (figura 6) já abrigou a Prefeitura Municipal de Sombrio desde 1954 até o ano de 1980. Somente no ano de 1990 a biblioteca recebe uma bibliotecária eleita através de concurso público. Nesse mesmo ano, também através de concurso, a biblioteca é renomeada como Biblioteca Pública Municipal Cônego João Reitz. Em 1992 volta para o prédio de origem, sendo que agora este estava reformado para seu uso exclusivo. A biblioteca só passa a receber verba específica para a compra de livros a partir de 2002.

No dia 16 de agosto de 2004 houve uma grade explosão no prédio ao lado da biblioteca, danificando muitos materiais e deixando-a sem condições de uso. Após cinco meses a administração municipal alugou outro espaço onde hoje se encontra a Casa da Cultura. E, finalmente no dia 20 de julho de 2007 é inaugurado o Prédio da Biblioteca 

impressa) ISSN: 2358-9426 (versão eletrônica)

todo reformado, com poucas características do prédio original, mas agora inclusivo com elevador, rampa, um espaço infantil e juvenil, e também com aquisição de computadores para pesquisa.

Figura 6 - Biblioteca Pública Municipal Cônego João Reitz.

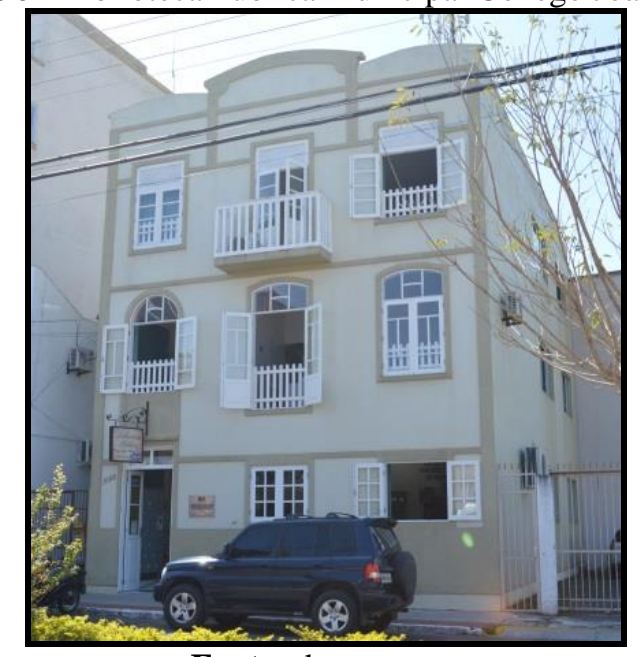

Fonte: dos autores.

No interior de Sombrio, mais especificamente na localidade de Garuva, se encontra a casa já centenária que pertence ao Sr. Servando Isoppo (figura 7) A edificação possui três andares: o primeiro todo de pedra, onde, segundo proprietário, servia de pouso para os tropeiros que ali passavam; no segundo andar inicia a casa, todo feito de madeira, onde ficava a cozinha, a sala e um quarto; o terceiro andar é baixo e bem perto do telhado, servindo também de quarto. A casa permanece em bom estado, porém tem pouca visibilidade, já que nenhum projeto foi realizado para garantir a preservação da edificação e da memória.

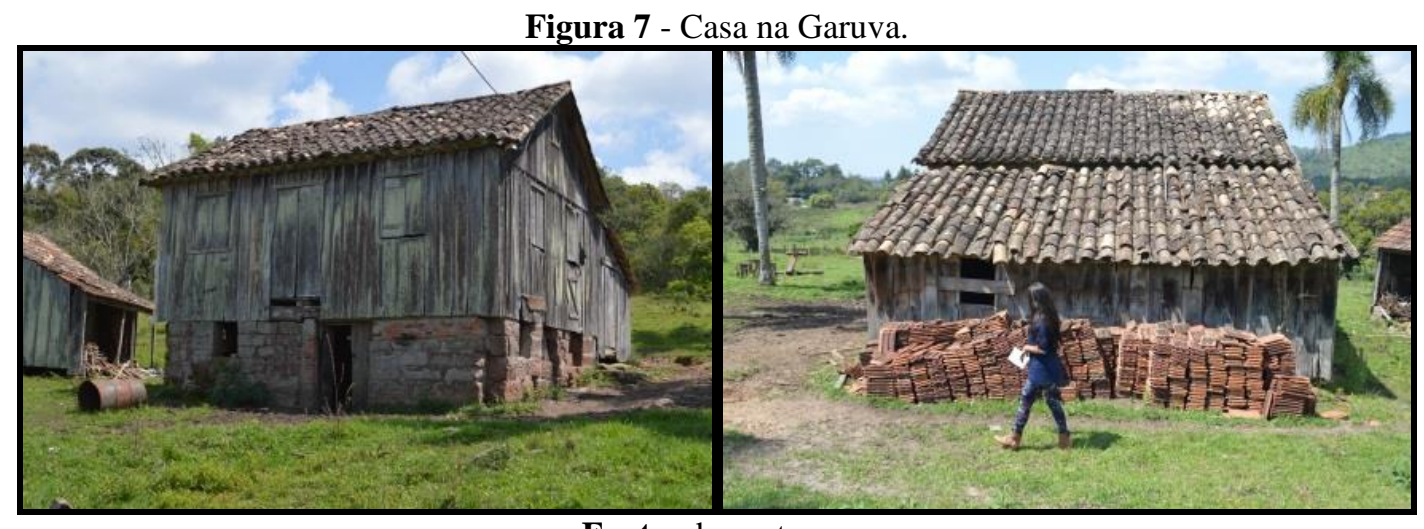

Fonte: dos autores. 

impressa) ISSN: 2358-9426 (versão eletrônica)

A casa tem mais de 80 anos e possui nove cômodos e uma área. Construída de tijolos maciços e telhas de barro, fica localizada bem perto da igreja e do campo de futebol da Guarita. Segundo o proprietário a edificação (figura 8) já foi um armazém e também uma fabrica de caixas de sapato - quando a produção de sapatos era a principal atividade industrial na cidade -, além de ser a casa da família. A casa está sofrendo desgastes. Uma parte do telhado já desmoronou.

Figura 8 - Casa na Guarita.

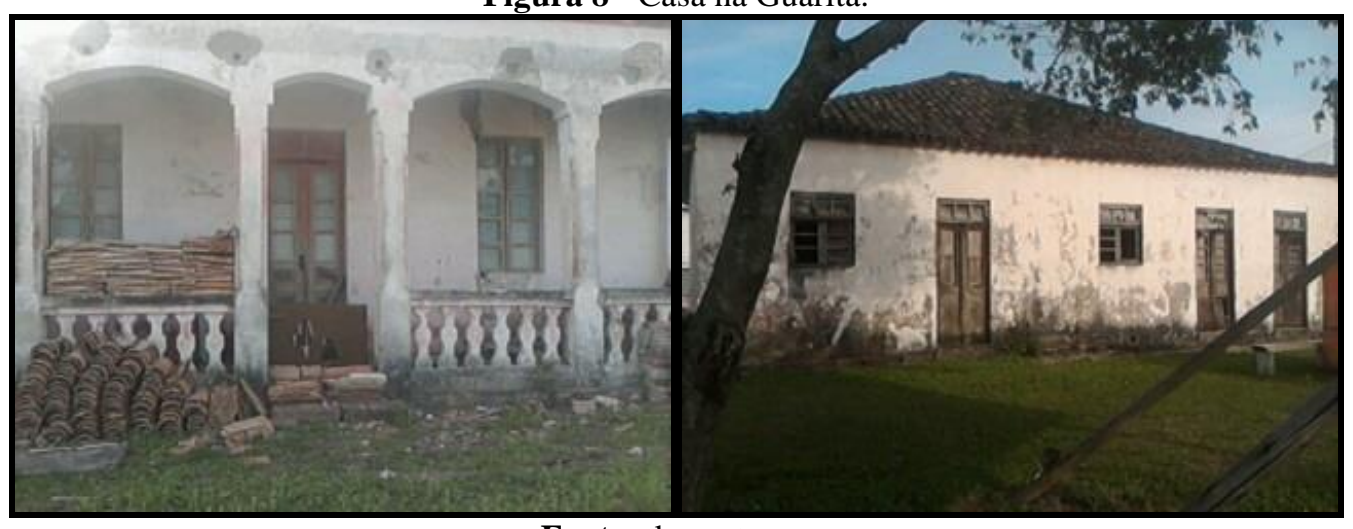

Fonte: dos autores.

Outro projeto do Pe. João Reitz era instalar em Sombrio uma escola de congregação religiosa feminina. Desde 1945 a Comissão Construtora da Matriz planejava a vinda das freiras para a sede da paróquia, oferecendo vantagens que pudessem garantir a permanência das "irmãs de caridade" na cidade. Dentre estas vantagens estavam "uma casa com terreno para se estabelecerem inicialmente, uma área com cerce de $6.000 \mathrm{~m}^{2}$ para a sede definitiva, a concessão dos bens do hospital para o domínio das irmãs..." (VALERIM, 1996, p. 120). Somente em 1956, 11 anos depois, a Congregação das Irmãs Sacramentinas de Bérgamo vem para Sombrio.

A 30 de setembro de 1956 chegaram em Sombrio as Irmãs Sacramentinas, de Bérgamo, que iniciaram o jardim da infância e a escola profissional junto a casa paroquial. Em 1963 receberam um terreno doado pela cúria de Tubarão, iniciando a construção de sua escola, que ficou concluída no ano de 1968 (PEREIRA, 1972, p. 83).

O IEMS - Instituto Educacional Madre Eliza Savoldi (figura 9), de caráter particular, além do jardim de infância fundou, “[...] a escola de $1^{\circ}$ e $2^{\circ}$ graus, o curso de datilografia, aulas de doutrina para a $1^{\circ}$ Comunhão e Crisma, curso de trabalhos manuais, supletivo de $1^{\circ}$ grau, entre outras atividades [...]" (VALERIM, 1996, p. 120). O Instituto Educacional até hoje é referência em ensino na cidade de Sombrio. 


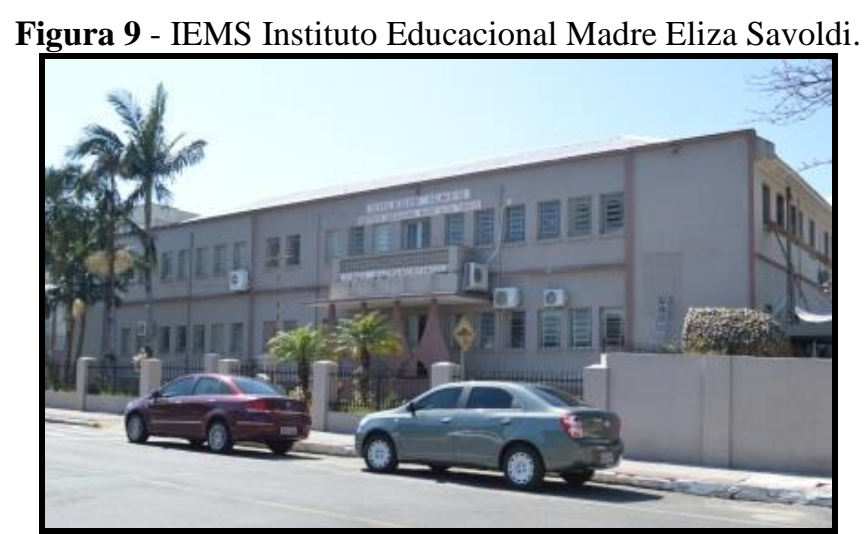

Fonte: dos autores.

A Escola estadual Catulo da Paixão Cearense (figura 10) foi a primeira construída em Sombrio, sua obra teve início no ano de 1947, porém relata-se que desde 1906 já havia pessoas que lecionavam, embora sem um ambiente físico específico (PEREIRA, 1972). Em 1941 o Pe. João Reitz funda a Sociedade Escolar de Sombrio, a fim de arrecadar recursos para a construção da escola da sede, sociedade esta que tinha como presidente o próprio Pe. João, com contribuição e pagamento de mensalidade dos membros da sociedade e com a venda de um prédio doado pelo Ipiranga Futebol Clube, por ocasião de sua extinção. A obra, iniciada em 1947, teve sua primeira turma concluinte em 1952. Hoje a escola Catulo da Paixão Cearense está reformada, porém foi mantida sua entrada original.

Figura 10 - Escola de Ensino Básico Catulo da Paixão Cearense.

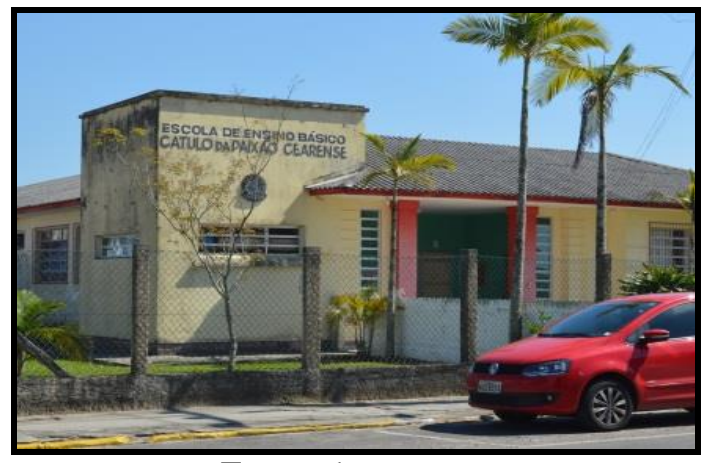

Fonte: dos autores.

O engenho (figura 11), que inicialmente só produzia farinha foi criado pelo Sr. Valdemiro Ramos, sendo repassado para seu filho Emilio Ramos, mais conhecido como Afonso, e hoje pertence a Eduardo Ramos, terceira geração desde seu fundador. Há aproximadamente uns 25 anos o engenho é de polvilho e farinha, a estrutura foi toda 
Revista Tecnologia e Ambiente, v. 21, 2014, Criciúma, Santa Catarina. ISSN: 1413-8131 (versão impressa) ISSN: 2358-9426 (versão eletrônica)

modificada e modernizada, pouco restando da construção inicial. $O$ engenho conta principalmente com o núcleo familiar para conseguir produzir. O poder público já visitou o engenho, no entanto nada de concreto em relação a reconhecimento como patrimônio tomou forca. Ainda que a produção do polvilho seja considerada símbolo da atividade econômica tradicional. O proprietário lembra que o engenho já foi movido primeiramente a boi e a cavalo, posteriormente a motor à óleo diesel e, finalmente, a energia elétrica.

Figura 11 - Engenho de Farinha.

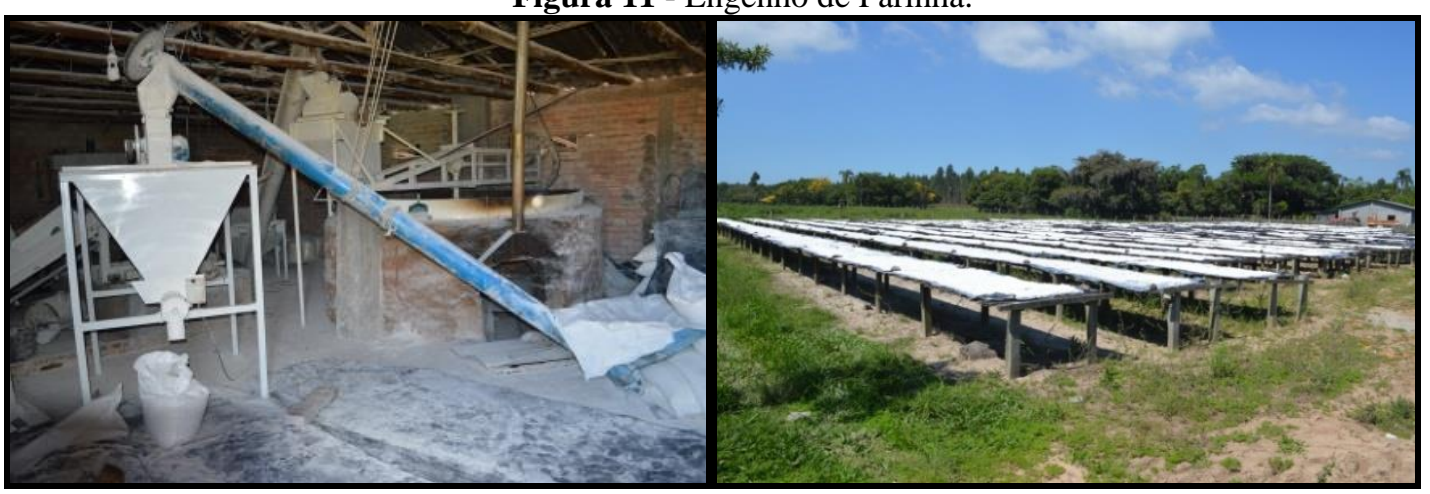

Fonte: dos autores.

Sabendo da importância do padre João, como é conhecido na Cidade, foi inaugurado em 05 de junho de 1988 um busto de bronze (figura 12) localizado ao lado da Igreja Matriz, “[...] por ocasião do $50^{\circ}$ ano de criação da Paróquia Santo Antônio de Pádua” (ROSA, 2012, p. 150). O busto foi esculpido por uma artista alemã amiga do Pe. João e foi doado à comunidade por seu irmão Pe. Raulino Reitz.

Figura 12 - Busto do Cônego João Adão Reitz.

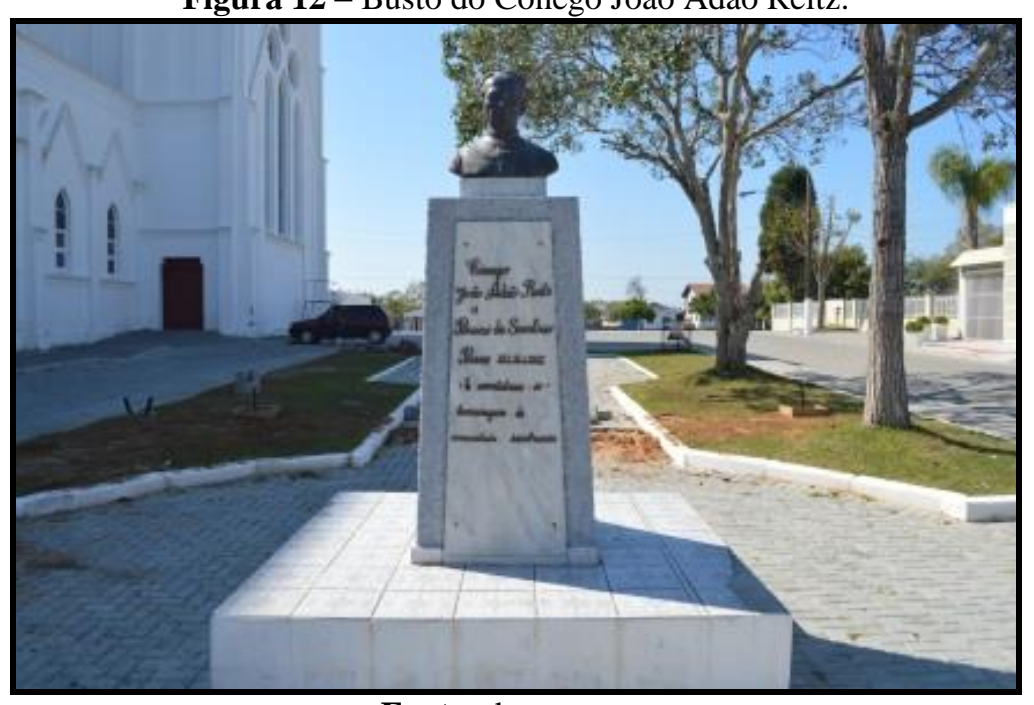

Fonte: dos autores. 
Revista Tecnologia e Ambiente, v. 21, 2014, Criciúma, Santa Catarina. ISSN: 1413-8131 (versão impressa) ISSN: 2358-9426 (versão eletrônica)

O Museu Étnico-Cultural ao Ar Livre (figura 13) em Sombrio é um ponto de referência, cultura e memória; nada se tem escrito sobre o mesmo e não possui nenhuma lei de proteção. O museu foi criado em 2000, mesmo ano do projeto Calçadão Cultural, realizado sob a administração do ex-prefeito Leopoldo Renato Alves da Silva, ele conta que os objetos foram doados por famílias da comunidade, e foram posteriormente restaurados. O museu é dividido em três setores, industrial, econômico e doméstico. No setor industrial estava a trilhadeira, que foi a primeira do seu tipo utilizada em Sombrio, doada pela família Turatti. E a Peça de Moenda de Alambique ou engenho de cana foi doada por uma família da comunidade de Sanga Negra. No setor econômico temos a pesca como economia de subsistência, representada pela canoa. A canoa do museu foi encontrada no fundo da Lagoa de Sombrio.

Hoje o museu encontrasse aquém dos cuidados que o mesmo merece. A comunidade pouco ou nada entende sobre as peças. Nenhum projeto foi realizado para dar visibilidade a este que legitima a cultura da população sombriense.

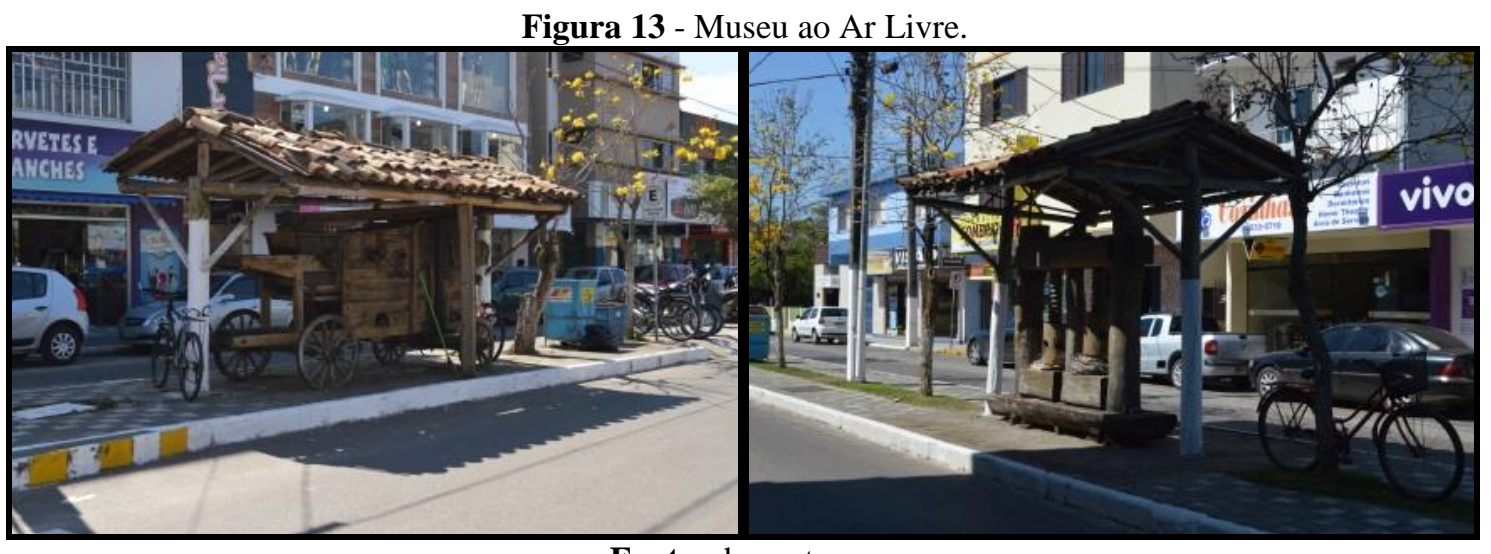

Fonte: dos autores.

Inaugurado no dia 8 de abril de 2000, o calçadão cultural (figura 14) pode ser considerado o ponto de referência mais conhecido e visitado da cidade, sendo a principal rua de comércio e cultura, pois em meio a tantas lojas os mosaicos no chão tentam retratar toda história do município.

Na série de cartões postais Caminho dos Canyons, aparece a importância do projeto para a cidade: "Inspirado na riqueza cultural que ainda resiste no cotidiano do município de Sombrio, no Sul de Santa Catarina, nasceu a ideia da reurbanização de um trecho da Av. Nereu Ramos, compreendido entre a rótula da Av. Getúlio Vargas e a Rua 
Caetano Lummertz. [...] A beleza do calçadão e o museu ao ar livre representam ao visitante a história local" ${ }^{* * *}$.

O projeto do Calçadão Cultural foi produzido pelo artista plástico Jone Cezar de Araújo. O projeto enfrentou muitas críticas na época, segundo conversa com Podinho. Este afirma que o próprio partido não o apoiou, nem compareceram na sua inauguração, apenas alguns da oposição que apoiaram. Podinho teve que contar com a ajuda da comunidade para arrecadação de fundos, debaixo de cada mosaico encontra-se uma placa de bronze com o nome de uma família ou empresa que fizeram, na época, uma doação de aproximadamente quinhentos reais para a construção. Além disso, Podinho contou com a ajuda das empresas Cardoso e Porto Belo, que forneceram os materiais (porcelanato) a preços de custo.

O projeto insere a cultura local no próprio cotidiano dos moradores da cidade, que ao passarem pelo centro se deparam com o Museu e com o Calçadão. "O projeto objetiva a criação de um calçadão onde, através de trabalho artístico baseado em referências históricas, culturais e ecológicas, se mostrará plasticamente, com mosaicos e esculturas, a rica cultura do povo de Sombrio" (ARAÚJO, s/d). Atualmente pretende-se retirar os mosaicos do calçadão e colocar no entorno da Igreja Matriz, onde inicialmente o projeto iria ser desenvolvido, mas na época não foi aceito.

O Calçadão também possui as esculturas em arame, que buscam através da arte representar a história do município. O projeto do Calçadão Cultural utilizou como referencia bibliográfica, os livros: "Uma Viagem no Tempo" de Vilson Francisco de Farias, "Os Romeiro de São Sebastião - A Cultura Açoriana no Sul Catarinense” de Rolando Chistian Sant'Helena Coelho, "Sua Origem, seu povo e sua tradição" de Juventino Januário Pereira, além do ensaio de uma monografia paroquial do Pe. Raulino Reitz e da monografia “O Imaginário Fantástico nas falas dos descendentes açorianos de Sombrio", produzido por Eliane Maria Vefago.

Todos os detalhes retratam um pouco da construção histórica da cidade de Sombrio. Os bancos no calçadão são de remos, os orelhões telefônicos são em formato de canoa e foram feitos em trabalho de ferro e cimento, lembrando que a pesca era um dos meios mais comuns de subsistência. Temos também um tear bem grande no meio da rótula no centro da cidade, esse instrumento é usado para a fabricação de tapetes,

\footnotetext{
${ }^{* *}$ Série Cartões Postais Caminho dos Canyons. Sombrio-SC. Coleção 20091001. Disponível no site: www.caminhodoscanyons.tur.br.
} 
Revista Tecnologia e Ambiente, v. 21, 2014, Criciúma, Santa Catarina. ISSN: 1413-8131 (versão impressa) ISSN: 2358-9426 (versão eletrônica)

atividade que foi trazida para a cidade de Sombrio pelos colonizadores açorianos, os fios de metal que representavam os fios de tecidos foram retirados do tear e não se sabe ao certo o fim que levaram. E não podemos esquecer os potes de cerâmica, que enfeitam o ambiente e nos remetem as olarias, atividade econômica ainda bem presente na região. Os postes de energia são decorados com mosaicos. A preocupação com a possível retirada dos mosaicos leva em conta todo seu entorno e seus detalhes.

Figura 14 - Calçadão Cultural.

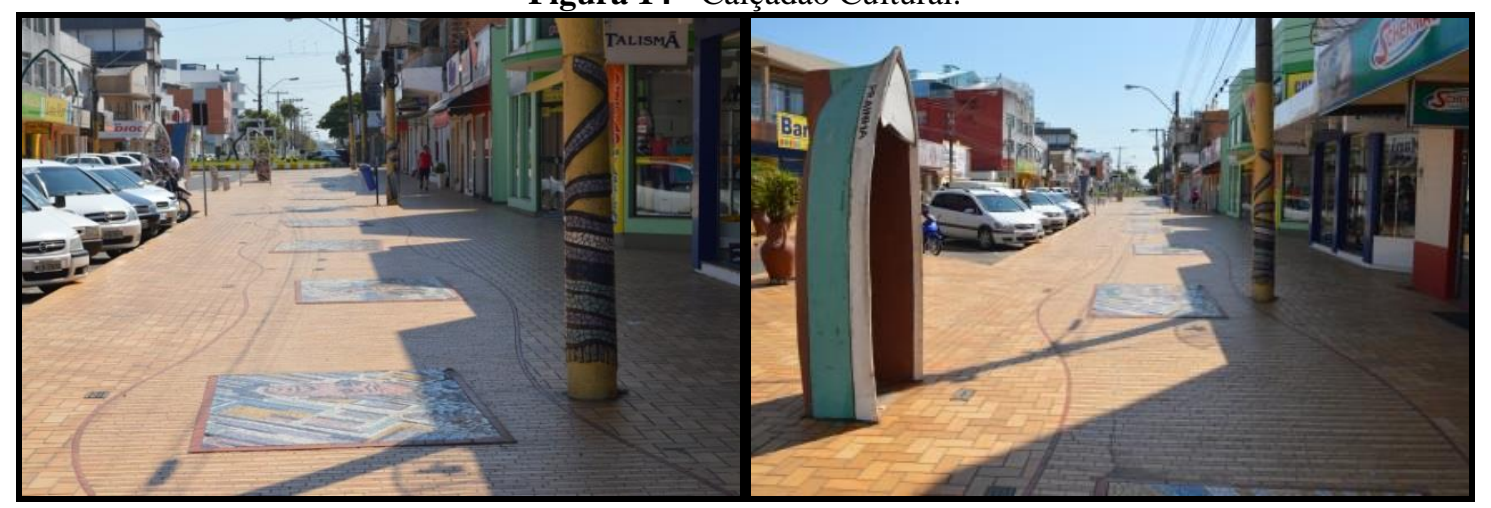

Fonte: dos autores.

\section{CONSIDERAÇÕES FINAIS}

Quando pensamos em revisitar os Patrimônios Históricos do munícipio de Sombrio, sabíamos que o assunto Patrimônio é pauta permanente nas ações políticas do poder público, fazendo parte de políticas e programas governamentais. Entretanto, sua operacionalização tem apresentado resultados pouco condizentes com a teoria, aja vista a situação dos patrimônios e o que se pensou em vários governos municipais.

$\mathrm{Na}$ tentativa de contribuir para políticas e iniciativas que sejam efetivamente eficientes, tivemos como um de nossos propósitos de atuar neste trabalho, além dos registros fotográficos e entrevista, revisitar os patrimônios e incluir na lista engenhos de farinha e outras edificações, que a nosso ver, tem e são potencialmente patrimônios históricos de Sombrio.

As políticas públicas no país, e em Sombrio não são diferentes, têm sido orientadas, com raras exceções, para as necessidades de crescimento econômico. Este entendimento parte da consideração de que os grupos humanos atuam essencialmente no espaço, sendo que o seu sucesso se pode medir pelo crescimento econômico que propicie um acesso crescente a bens materiais de diversos tipos. Daqui decorre o 
interesse em articular interesses desse crescimento na organização do espaço, de forma a harmonizar as suas respectivas agendas em prol de um futuro convergente e comum (OOSTERBEEK et al., 2010, p. 29-30).

Procuramos, através deste trabalho, fazer com que haja, na medida do possível, um avanço da participação dos cidadãos na vida da sociedade. Por um lado, entendemos que o potencial edificado para o patrimônio existe, por outro, percebe-se uma tímida política para a real atenção ao problema patrimonial.

Percebemos no decorrer do trabalho a combinação dos processos de crescente participação (ou vontade de participação) da população e de setores idealistas do poder público, com a crescente impotência deste mesmo poder público para providenciar soluções para os problemas elementares que afetam os indivíduos, e aqui incluímos a cultura, a emergência de novos desejos, como revitalizar o calçadão central de Sombrio, num quadro em que o crescimento se torna possível graças à inovação tecnológica, mas em que esta gera, a cada dia, menor necessidade de postos de trabalho e o reforço da integração sistêmica das realidades regionais através das novas tecnologias, perpassam pela revitalização histórica de nossa história, nossa identidade e nossa memória. Todos estes processos reforçam o espaço de intervenção de indivíduos isolados ou pequenos grupos, numa escala sem precedentes.

Nesse processo, o reconhecimento da diversidade cultural não apenas como um direito, mas como uma força da nossa espécie, será essencial no futuro, o que nos leva à dimensão das identidades.

Enfim, a reapropriação de territórios de patrimônios ou de repatriamento de bens é outro elemento gerador de crescentes debates de raiz identitária, que depois podem vir a ser transformados em grandes projetos ou esquecidos pela gestão governamental. Definimos os conceitos, contextualizamos o tema, o município, e revisitamos os patrimônios; logo, acreditamos no trabalho dos pesquisadores na construção de uma consciência política, para assim fazer uma sociedade comprometida com sua identidade.

\section{REFERÊNCIAS}

ARAÚJO, Jone Cezar de. Projeto de criação do calçadão em Sombrio. Biblioteca Pública Municipal Cônego João Reitz. S/d. 
ARGAN, Giulio Carlo. Patrimônio Edificado: um livro em forma de arquitetura. Projeto de Educação Patrimonial, Bahia, 2013. Disponível em: <http://www.ipac.ba.gov.br/wp-content/uploads/2011/11/patrimonio-edificado.pdf>. Acesso em: 11 de out. 2013.

BOSI, Ecléa. Memória e Sociedade: lembranças de velhos. São Paulo: Edusp, 1987.

BURKE, Peter. Variedades da história Cultural. Tradução: Alda Porto. Rio de Janeiro: Civilização Brasileira, 2000.

BURKE, Peter. A escola de Annales. São Paulo: ed. UNESP, 1997.

FARIAS, Vilson Francisco de. Sombrio: 85 anos: natureza, história e cultura: para o ensino fundamental. Sombrio: Ed. do autor, 2000.

FUNARI, Pedro Paulo; CARVALHO, Aline Vieira de. Cultura Material e Patrimônio Cientifico: Discussões Atuais. Cultura Material e Patrimonial de C\&T, Rio de Janeiro, 2013.2 Disponível em:<http://www.mast.br/projetovalorizacao/textos/livro\%20cultura $\% 20$ material $\% 20 \mathrm{e} \%$ 20patrim\%C3\%B4nio\%20de\%20C\&T/2\%20ARTIGO\%20Pedro\%20Paulo\%20Funari.p df>. Acesso em: 01 de out. 13.

GHIRARDELlO, Nilson; SPISSO, Beatriz. Patrimônio histórico: como e por que preservar. Bauru, São Paulo: Canal 6, 2008.

Halbwachs, Maurice. A Memória Coletiva. Tradução Laurent Leon Schaffter. São Paulo: Vértice; Editora: Revista dos Tribunais, 1990.

HOBSBAWN, E. A Era dos Extremos: o breve século XX: 1914-1991. Trad. Marcos Santarrita. São Paulo: Cia das Letras, 1995.

HORTA, Maria L. P.; GRUNBERG, Evelina; MONTEIRO, Adriane Queiroz. Guia Básico de Educação Patrimonial. Brasília: Instituto do Patrimônio Histórico e Artístico Nacional, Museu Imperial, 1999.

IBGE - Instituto Brasileiro de Geografia e Estatística. IBGE Cidades. Sombrio/SC. Disponível em: $<$ http://cidades.ibge.gov.br/xtras/perfil.php?lang=\& codmun=421770\&search=||infogr\% E1ficos:-informa\%E7\%F5es-completas>. Acesso em: 31 de out. 2013.

Informativo AABP. No 01 julho de 2006. Sombrio. Gráfica Azes.Série Cartões Postais Caminho dos Canyons. Sombrio-SC. Coleção 2009\001. Disponível em: <www.caminhodoscanyons.tur.br>. Acesso em: 10 de nov. 2013.

IPAT/UNESC. Diagnóstico do patrimônio arqueológico e histórico do município de Criciúma: subsídios para o planejamento urbano. Portaria $\mathrm{n}^{\circ} 263,30$ de agosto de 2006.

MARTINS, Maria Helena Pires. Preservando o patrimônio e construindo a identidade. São Paulo: Moderna, 2001.

MINAYO, Maria Cecilia de Souza. Pesquisa social: teoria, método e criatividade. Ed. Petrópolis: Vozes, 2003.

MONTENEGRO, Antonio Torres. História Oral: Caminhos e descaminhos. Revista Brasileira de História, São Paulo, n. 25/26, 1992. 
OOSTERBEEK, L.; SCHEUNEMANN, I. Falsas contradições entre crescimento e desenvolvimento. Custo Brasil. Soluções para o Desenvolvimento, ano 5, n. 25, fev.mar. 2010.

OSTETTO, Lucy Cristina; COSTA, Marli de Oliveira. Circulando por lugares sagrados: reconhecendo a memória religiosa de Criciúma. Criciúma, SC: UNESC 2001.

PENSAVENTO, Sandra Jatahy. História \& História Cultural. 2. ed.. Belo Horizonte: Autêntica, 2005.

PEREIRA, Juventino Januário. Sua origem, seu povo e sua tradição. Canoas-RS: Ed. La Salle, 1972.

PORTELLI, Alessandro. Tentando aprender um pouquinho: algumas reflexões sobre ética e história oral. Projeto História, São Paulo, n. 15, abril/1997.

Prefeitura Municipal de Sombrio. Lei no 1080, de 14 de junho de 1996. Disponível em: <www.leismunicipais.com.br>.Acesso: 01 de nov. de 2013.

Prefeitura Municipal de Sombrio. Lei no 1402 de 20 de março de 2003. Disponível em: <www.leismunicipais.com.br>. Acesso em: 01 de nov. de 2013.

ROSA, Oníria Santos da. Os nossos antepassados: garra, fé e compromisso: Paróquia Santo Antônio de Pádua (documentário). Blumenau: Ed. 3 de maio, 2012.

SALVADORI, Maria Ângela Borges. História, ensino e patrimônio. Araraqura, São Paulo: Juqueira\&Marin, 2008.

SILVA, Fernando Fernandes da. As cidades brasileiras e o patrimônio cultural da humanidade. São Paulo: Peirópolis: Editora da Universidade de São Paulo, 2012.

SILVA, Osvaldo Paulino da. Arqueologia dos engenhos da Ilha de Santa Catarina. Erechim, RS: Habilis, 2007.

THOMPSON, E. P. Intervalo: A Lógica Histórica: In: THOMPSON, E. P. A Miséria da teoria: Ou um planetário de erros. Rio de Janeiro: Zahar, 1981.

VALERIM, Vera Regina Alves. A cura das almas: Padre João Reitz e a comunidade da Paróquia de Sombrio (1938-1963). Monografia. Florianópolis-SC. 1996. 